\title{
Santa Teresa de Jesús en Rumanía. Entrevista a Christian Tămaș, traductor al rumano de las obras de Santa Teresa ${ }^{\top}$
}

\section{Santa Teresa de Jesús in Romania. Interview with Christian Tămaș, the Translator into Romanian of St.Teresa's Works}

\section{Amelia Sandu-Andrieș}

Universidad «Al. I. Cuza», Iași

RUMANÍA

ameliasanduandries@yahoo.fr

[Hipogrifo, (issn: 2328-1308), 3.1 , 2015, pp. 257-266]

Recibido: 27-03-2015

DOI: http://dx.doi.org/10.13035/H.2015.03.01.16

Resumen. Teresa de Jesús vivió en el complicado siglo XVI español: una vida dedicada a la obediencia, la fundación de monasterios carmelitas y la escritura. La presente entrevista (modesto homenaje con motivo de los 500 años del nacimiento de la santa), nos permite un acercamiento a esta insigne personalidad de la literatura religiosa occidental desde la perspectiva del traductor de su obra al rumano. Catedrático de lengua y literatura árabe, novelista y traductor de italiano, catalán, francés, árabe, español, portugués, gaélico irlandés e inglés, Christian Tămaș publicó, entre 1994 y 1998, cuatro de las obras esenciales de la escritora española, llevadas por primera vez ante el público rumano. Testigo lúcido de aquellos años de apertura y curiosidad intelectual, el traductor evoca aspectos relacionados con la recepción de la escritora en Rumanía, las dificultades del texto teresiano, el papel de la traducción religiosa, el estado actual del acto de lectura, las luces y las sombras de la sociedad rumana de hoy en día.

Palabras clave. Santa Teresa de Jesús, Christian Tămaș, recepción en Rumanía, traducción de textos religiosos.

1. Traducción al español del texto original en rumano: Amelia Sandu-Andrieș. 
Abstract. Saint Theresa of Ávila lived in Spain, during the complicated XVIth century. A life of obedience, dedicated to writing and to the foundation of Carmelite monasteries. The present interview (a modest homage upon the celebration of 500 years since the birth of the saint) allows us to approach the life and works of a top rank personality of the Occidental religious literature from the perspective of a translator, more precisely from the perspective of the man who transposed her words into Romanian. A specialist in Arabic language and literature, a novelist and translator from Italian, Catalan, French, Arabic, Spanish, Portuguese, Irish and English, Christian Tămaș published, between 1994 and 1998, four of the main works of the Spanish writer, being the first to present her thoughts and ideas to the Romanian reader at that time. A lucid witness of times when openness and intelectual curiosity were highly valued, the translator evokes certain aspects regarding the way in which she has been perceived in Romania, pinpointing the difficulty of the Theresian text and speaking of the role of religious translation, the present state of the act of reading, the lights and shadows of a society -the modern day, Romanian one.

Keywords. Saint Teresa of Ávila, Christian Tămaș, Romanian Perception, Religious Translations.

Christian Tămaș (n. 1964), licenciado en lengua y literatura árabe (Universidad de Bucarest), doctor en filosofía (Universidad «Al. I. Cuza» de lași) y autor de importantes estudios de especialidad, entre los cuales se pueden destacar: Crize contemporane: Disolu ia sacrului (Ars Longa, 2003); Crize contemporane: Ofensiva islamului (Ars Longa, 2004); Strategii de comunicare în Coran (Ars Longa, 2007); Communication Strategies in the Qur'an (Lambert Academic Publishing, 2011); El. Avatarurile unui articol hotărât (Ars Longa, 2012); Modelul medinian și islamul global (Ars Longa, 2014).

AMELIA SANDU-ANDRIEȘ. Usted es catedrático de lengua y literatura árabe, especialista por tanto en una cultura que guarda poca relación con la mística occidental. ¿Qué significa para usted traducir del español? ¿Por qué eligió traducir al rumano las obras (casi) completas de Santa Teresa de Jesús?

CHRISTIAN TĂMAȘ. Efectivamente, soy especialista en lengua y literatura árabe, pero me atrevo a decir que me muevo con igual facilidad en otras siete lenguas y sus correspondientes culturas. Los casi 80 libros que he traducido y publicado en los últimos 25 años (traducciones del español, árabe, gaélico irlandés, francés, inglés, catalán, italiano o portugués) han significado para mí una permanente búsqueda de comunicación con el «Otro», de comprensión, con el objeto de transponer de forma correcta su espacio y tiempo, su universo interior y exterior.

A Santa Teresa, no creo haberla elegido yo, más bien fue ella quien me eligió a mí. Es lo que a menudo acontece, nos demos cuenta o no, lo reconozcamos o no, con los asuntos que conciernen de un modo directo a Dios. Independientemente de lo dicho, consideraba que la sociedad rumana de los años noventa del siglo pasado, cuando se publicaron por vez primera mis traducciones de las obras 
de Santa Teresa (Cartea vieții, 1994; Castelul interior și Drumul perfecțiunii,1995; Întemeierile,1998)², necesitaba grandemente este tipo de literatura. El cambio radical producido tras los acontecimientos de diciembre de 1989 había despertado, en lo espiritual, un gran ansia por todo aquello que había estado prohibido y/o desconocido hasta entonces. La sociedad rumana de esa época me evoca a Gargantúa, el célebre personaje de Rabelais quien, nada más nacer, clamaba con su no menos célebre «À boire!», su sed; en nuestro caso, sed de saber, de conocer. En la Rumanía de aquel entonces, pese a ciertos malentendidos generadores de convulsiones, la libertad se dejaba palpar, incluso en las cuestiones religiosas. La Iglesia romanocatólica y las Iglesias protestantes iban reoganizándose. La Iglesia greco-católica de Transilvania, prohibida por los comunistas en 1948, estaba renaciendo mientras que la Iglesia ortodoxa, echándose cenizas en la cabeza, construía nuevos templos para así redimir los que habían sido derribados con su venia, reflejo de la pusilanimidad o las debilidades humanas. En un período como ése, los escritos de santa Teresa, al igual que de otros santos occidentales y orientales, aspiraban a reponer al Creador en el lugar que le habían quitado. Emprendí la traducción de las obras de santa Teresa como responsabilidad de hacer consciente al ser humano de su calidad de hijo de Dios, según mis pocas fuerzas.

AMELIA SANDU-ANDRIEȘ. Cuando usted inició la traducción al rumano de las obras de Santa Teresa, ¿cómo se presentaba el panorama de su recepción en Rumanía?

CHRISTIAN TĂMAȘ. En 1994, cuando vio la luz mi traducción del Libro de la vida, el gran público lo desconocía casi todo acerca de santa Teresa. Los católicos (tanto los de rito latino como los de rito bizantino de Transilvania) eran igualmente desconocedores del tema. Se sabía, a grandes rasgos, que se trataba de una santa del calendario litúrgico y poco más. En la época, a muchos les resultaba más popular, incluso más importante, otra santa Teresa, la del Niño Jesús.

AMELIA SANDU-ANDRIEȘ. ¿Qué dificultades tuvo que sortear a la hora de traducir el texto teresiano a la lengua rumana?

CHRISTIAN TĂMAȘ. Para que un autor sea correctamente recibido en una cultura diferente a la original, hace falta no una traducción, sino una transposición a otro contexto cultural, de forma que el texto corresponda al horizonte de expectativas de sus nuevos lectores, sin que el proceso perjudique en nada su individualidad. Dicho de otra forma, el autor ha de crear la impresión de haber escrito directamente en la lengua a la que fue, en realidad, traducido. Cuando se trata de un autor religioso, las cosas se complican aún más. En Rumanía, el lenguaje teológico es ortodoxo, con abundancia de vocablos de origen eslavo y, en menor medida, griego. La lengua literaria naturalizó dichos vocablos, hace ya tiempo. Existe asimismo un lenguaje romano-católico, situado en las antípodas del ortodoxo y marcado por neologismos, calcos y barbarismos de origen latino, préstamos indirectos, llegados a través del italiano moderno e insertados a veces a la fuerza en la lengua rumana. Existe, además, un lenguaje greco-católico, también forzado, que pretende mantener una

2. Libro de la vida, El castillo interior, Camino de perfección, Las fundaciones. 
vía media entre el lenguaje religioso ortodoxo y el romano-católico. Y no hablemos del lenguaje protestante.

Volviendo a la traducción al rumano de las obras de santa Teresa, las dificultades consistieron no tanto en el estilo y la arquitectura de la frase teresiana, que procuré y, en gran medida, creo haber logrado, mantener, sino en el léxico, en encontrar los elementos léxicos más idóneos que permitieran una recepción correcta en mi país de los escritos de la santa, por parte de todos los públicos, laicos y religiosos en igual proporción.

AMELIA SANDU-ANDRIES. ¿Cuál de los libros de santa Teresa se resistió más al proceso de traducción, cuál necesitó más tiempo de reflexión, de interpretación? ¿En cuál le costó más trabajo encontrar el equivalente justo en rumano?

CHRISTIAN TĂMAȘ. A buen seguro, Libro de la vida. Era mi primer contacto directo con el universo teresiano.

AMELIA SANDU-ANDRIEȘ. Estamos ante una escritura que pone en marcha recursos interiores, que remueve por dentro toda la intimidad espiritual de la persona que se le acerca. ¿En qué medida se implicó usted en la tarea de traducir, teniendo en cuenta que no se trata de un texto cualquiera?

CHRISTIAN TĂMAȘ. Yo no puedo traducir un texto cualquiera. Dicho de otro modo, no traduzco sino lo que considero que merece ser traducido, lo que puede llevar a enriquecer, espiritualmente hablando, al ser humano. Al traducir, intento entrar en la intimidad del autor, en su mente y su espíritu, tal como se me descubren más allá de las palabras; me introduzco en su época y en el interior de los personajes que le dan vida, para así comprenderlos y ser capaz de comunicarlos. Es lo que hice en el caso de Santa Teresa.

AMELIA SANDU-ANDRIEȘ. ¿Qué le impresionó en sus escritos?

CHRISTIAN TĂMAȘ. El amor por Dios. El amor de Dios. El hecho de que Él habla hasta cuando calla y que está presente en todo, en los más mínimos, en los más nimios sucesos de nuestra vida.

AMELIA SANDU-ANDRIEȘ. ¿Cómo caracterizaría usted a esta escritora? ¿La considera un modelo humano? ¿Qué valores podría transmitirnos hoy en día una persona como ella?

CHRISTIAN TĂMAȘ. Santa Teresa decía de sí misma que escribía tal como hablaba: un estilo coloquial, directo, espontáneo, con pocos artificios y un carácter casi plástico de la expresión. Como persona, si nos atenemos a su actividad, la reformadora del Carmelo era una mujer que rebosaba sensibilidad, habilidad y fuerza, combinando los arrebatos místicos con el espíritu práctico, era la «piedra imán que a todos atrae», tal como la definía fray Luis de León.

¿Qué nos podría transmitir ahora, después de tanto tiempo? El ejemplo de toda una vida de trabajo, su amor a Dios, la tenacidad y valentía de nadar siempre contra la corriente, en un mundo globalizado, manipulado, materialista, superficial y exento casi por completo de cualquier horizonte transcendental. 
AMELIA SANDU-ANDRIEȘ. Volviendo a la perspectiva cronológica, nos situamos en el siglo XVI, en un contexto histórico y cultural específico, con una política de consolidación de los estados nacionales, en que el castellano, en tanto que símbolo de la monarquía católica, se ve reforzado tras la finalización de la Reconquista, cuyos ecos aún se sienten en nuestra escritora. ¿En qué medida es la obra de santa Teresa un producto de su época?

CHRISTIAN TĂMAȘ. En gran medida, efectivamente. La época de santa Teresa fue una época de grandes cambios a nivel europeo. Desde el punto de vista institucional, la Iglesia católica había entrado en una fase aguda de decadencia moral. En 1517, cuando la futura Santa tenía dos años, Martin Lutero redactaba sus famosas 95 Tesis, que habían de marcar el comienzo oficial del Cisma de Occidente, entre católicos y protestantes. En 1524 empezaban las Guerras de Religión, siendo las más señaladas la Guerra de Esmalcada (1546-1547), en el interior del Sacro Imperio romano-germánico, entre las fuerzas del emperador Carlos V (al mismo tiempo rey de España, con el nombre de Carlos I) y la Liga de Esmalcada, integrada por príncipes protestantes; y, especialmente, la Guerra de 80 años (1568-1648) de los Países Bajos. A nivel interno, la Reconquista había concluido poco tiempo antes (1492). España aspiraba, por una parte, a consolidarse como reino y, por otra parte, a afirmar su influencia en el continente. En lo espiritual, la Inquisición representaba una institución temible; sin embargo, el laxismo religioso constituía una constante, lo que había llevado a la aparición de movimientos místicos diversos, como lo fue, por ejemplo, el de los alumbrados, con un gnosticismo de índole italiana, o incluso el surgimiento de grupos protestantes.

En un contexto de este tipo, y pese a los peligros reales que corría por su origen familiar (pues aunque la santa venía de una tercera generación de judíos conversos al catolicismo, los conversos seguían siendo vigilados de cerca por la Inquisición, y fácilmente acusados de apostasía) y pese a que las mujeres estaban consideradas como faltas de inteligencia, de naturaleza flaca y susceptibles de dejarse seducir por el diablo sin oponer resistencia, y sin contar con que entre los alumbrados, juzgados como heréticos, se encontraban numerosas mujeres, Teresa, guiada por Dios, intuyó de forma admirable que la Iglesia sólo se podía salvar volviendo a sus raíces originarias. Esta convicción constituirá la base misma de la obra teresiana, orientada hacia la reforma de la Orden carmelita e, indirectamente, de la Iglesia en su conjunto. Gracias a los esfuerzos de Teresa de Jesús, de Ignacio de Loyola y de otros, la Contrarreforma iba plenamente a surtir efecto.

AMELIA SANDU-ANDRIEș. Los textos de santa Teresa dicen mucho. Pero, ¿cuánto callan? ¿Qué dejan al lector como tarea de reflexión, de descubrimiento? ¿Son los silencios importantes en un texto?

CHRISTIAN TĂMAȘ. Los escritos de santa Teresa callan cuanto quiso la autora callar. Por ejemplo, su origen hebraico. U otras cosas que prefiere, por prudencia, no escribir, sino comunicar de viva voz, de persona a persona. Muchas de las omisiones intencionadas de los escritos teresianos se ven explicadas por la santa en sus cartas. Estas cartas aún no se han traducido al rumano. Me pregunta usted si los silencios son importantes en un texto. Sí, lo son, en la medida en que estimulan 
al lector a llenarlos por sí mismo. Todo depende, empero, de la intención del autor, de cuánto quiere o no quiere él decir.

AMELIA SANDU-ANDRIEȘ. El lenguaje supone comunicación del Yo y, sobre todo, alteridad, intercomunicación. ¿Son los escritos de santa Teresa de sentido único (la autora, obedeciendo la orden de sus superiores, tiene algo que decir y lo dice) o son escritos de doble sentido, en donde el lector se encuentra a sí mismo, a través del autor y puede, a su vez, compartir sus vivencias con otros? ¿Se puede observar en santa Teresa una alegría de la escritura?

CHRISTIAN TĂMAȘ. Siempre que uno escribe, comunica con su lector, real o hipotético, se le comunica. El lector es susceptible de comunicar, más adelante, al escritor, esté o no esté de acuerdo en todo con su punto de vista. No tiene mucha importancia si uno escribe por imperativo propio o si, todo lo contrario, un tercero cualquiera lo mueve o lo obliga a ello. Lo que importa es tener algo que comunicar, un mensaje que transmitir y luego, evidentemente, saber transmitirlo de tal forma que pueda ser recibido, valorado y aprovechado. En este supuesto, se dará también la alegría de la escritura. En santa Teresa, quizás más que una alegría de la escritura, se siente la alegría de la misión cumplida.

AMELIA SANDU-ANDRIEȘ. Además de santa Teresa, usted tradujo los Ejercicios espirituales de San Ignacio de Loyola. ¿Fue una experiencia traductológica diferente?

CHRISTIAN TĂMAȘ. Sí. Los Ejercicios espirituales de san Ignacio de Loyola difieren mucho de los escritos de santa Teresa. Los Ejercicios representan un manual, una guía compuesta por una serie de meditaciones, oraciones y ejercicios de concentración que se desarrollan a lo largo de unos 28 o 30 días y que, para ser efectivos, se deben realizar bajo la dirección de un director espiritual. Los Ejercicios encuentran su razón de ser en el propósito de formar, en lo espiritual, a los jóvenes integrantes de la Orden Jesuita. A diferencia de los escritos de santa Teresa, los Ejercicios ignacianos carecen casi por completo de valor literario. San Ignacio era un soldado y escribía como tal. La lengua de los Ejercicios es una sin pulir, algo tosca, con errores de expresión. Desde el punto de vista estilístico, sobresale a veces por la concisión casi espartana y la energía con que llega a expresar determinadas ideas, pero poco más. Lo importante aquí es el contenido, y menos sus vestimentas. Para el traductor, representa un esfuerzo complementario, tanto en cuanto a la comprensión correcta de la idea, como en cuanto a su transposición, su adecuación. Debemos tener en cuenta, además, que los Ejercicios no se dirigen al gran público.

AMELIA SANDU-ANDRIEȘ. ¿ES importante que el traductor ame el texto de partida, que empatice con el autor, que comparta su pensamiento, que conozca en detalle su biografía, que sea, en última instancia, una «prolongación» del autor?

CHRISTIAN TĂMAȘ. Depende del tipo de texto. Si no se trata de un texto literario, la respuesta es no. Ni siquiera en el caso de la literatura es condición obligatoria. Resulta suficiente que el traductor conozca muy bien la lengua de partida y la lengua de llegada, con todas sus sutilezas. Además, debe moverse a la perfección en el contexto cultural de la obra que traduce. El que yo me implique más en el caso 
de las traducciones literarias es, supongo, una cuestión de opción personal. Esta implicación tiene, lógicamente, sus límites. El traductor no debe hacer al autor más grande de lo que en realidad es, pero tampoco disminuir su valor, con la traducción ofrecida. Si no quiere que le griten: Traduttore, traditore!, como se dice que les gritaron los italianos a los franceses cuando éstos últimos tradujeron por primera vez la obra de Dante. Una traición, por más mínima que sea, existe empero en toda traducción. Es imposible conservar intactos el fondo y la forma. El traductor debe orientarse: a veces es preferible conservar lo uno, otras veces lo otro. O puede sacrificar algo de cada, a partes aproximadamente iguales... dependiendo del texto. Pero de ninguna forma se ha de sustituir al autor, completarlo. Si es lo que pretende, nada le impide ponerse él mismo a escribir. Si es que tiene madera de escritor, claro.

AMELIA SANDU-ANDRIEȘ. ¿ES necesario que el traductor de textos religiosos pertenezca a la misma tradición religiosa que el autor traducido?

CHRISTIAN TĂMAȘ. No creo necesario que siga la misma tradición, creencia, ni siquiera la misma religión. Incluso puede ser ateo. De hecho, conozco a varias personas de esta última categoría que han traducido textos religiosos de modo admirable. Los problemas de conciencia, si es que surgen, no tienen nada que ver con el acto en sí de traducir. Yo, por ejemplo, no traduciría jamás ni publicaría un texto que pudiera alejar al hombre de Dios y de los fundamentos ético-morales que nos definen como humanos. Y no sería por falta de medios para traducir con alta calidad dicho texto, sino porque las consecuencias de este bien inmediato (la traducción del texto) no fueran a constituir, desde el punto de vista moral, un mal. En uno de sus libros, titulado «Ayuda a mi poca fe» ${ }^{3}$, el jesuita irlandés Michael Paul Gallagher refería un suceso cuyo protagonista había sido: una noche, al cruzar una calle y viendo a un hombre delante de un patio, muy ajetreado en su intento de pasar un pesado saco por encima de la valla, se apresuró a echarle una mano. Una vez lejos el hombre con su saco, nuestro autor se preguntó si el desconocido al que había ayudado no era, en realidad, un ladrón que acababa de saquear una casa y se preparaba a huir con el botín. El bien hecho era, en ese caso, un mal. Lo mismo, más o menos, me sucede a mí.

AMELIA SANDU-ANDRIEȘ. ¿Cuál es el papel de la traducción, en general y en el caso concreto de nuestra autora? ¿Instrumento mediato de conocimiento?

CHRISTIAN TĂMAș. Sí, tanto en el caso de santa Teresa como en general, éste es el papel esencial de la traducción: conocer al «Otro», comprenderlo en tanto que nuestro alter ego.

AMELIA SANDU-ANDRIEȘ. ¿Para quién traduce usted? Al traducir, ¿piensa en un determinado tipo de público?

CHRISTIAN TĂMAȘ. Traduzco para el autor y para el lector, en la misma proporción. Para dar a conocer al autor. Para que el lector conozca lo que merece ser conocido, o al menos lo que yo valoro como tal. Para que tanto el uno como el otro

3. Título original: Help my unbelief. 
Ileguen a tratarse y comprenderse. No traduzco para un público especial. Traduzco para los espíritus abiertos y los buenos entendedores.

AMELIA SANDU-ANDRIEȘ. ¿Las editoriales que publicaron sus trabajos le condicionaron de alguna forma? ¿En qué medida una editorial puede influir en una traducción?

CHRISTIAN TĂMAȘ. La condición conciernía exclusivamente el plazo de entrega del trabajo. La editorial evalúa si una traducción merece ser publicada, teniendo en cuenta el valor de mercado del texto en causa, es decir, el interés que podría despertar entre los lectores. A partir de ahí, decide publicar o dejar de publicar. Por desgracia, la base de su decisión la representa menos el valor intrínseco del texto cuanto su valor comercial añadido. No siempre es culpa de la editorial. Son las normas del mundo en que vivimos. A menudo, la editorial reconoce el valor de un libro, sin poder publicarlo porque su opinión no se ve compartida sino mínimamente (o en absoluto) por el destinatario del libro, a saber, por el lector. En términos ideales, una editorial que pretende ser una institución cultural y no sólo comercial, se ha de esforzar en difundir y dar a conocer sus valoraciones relativas al mérito de tal o tal autor, de tal o tal obra. En realidad, no logrará hacerse entender a falta de una implicación seria de la familia, la escuela, la Iglesia y los demás formadores presentes en la sociedad.

AMELIA SANDU-ANDRIEȘ. ¿Cambiaría algo de lo que tradujo?

CHRISTIAN TĂMAȘ. No lo sé. A lo mejor. A condición de volver a leer lo que he traducido en las últimas décadas. Hasta hoy, los libros que he publicado, originales míos o traducciones, suman más de trece mil quinientas páginas, de forma que nunca he tenido tiempo para hacerlo. Tampoco creo que lo tenga de ahora en adelante. Queda mucho por escribir, por traducir.

AMELIA SANDU-ANDRIEȘ. En tanto que especialista en una lengua y una cultura relativamente marginalizadas, y que salen a superficie casi en exclusiva como productoras de pánico (estoy hablando del árabe), ¿conoce usted si la literatura religiosa occidental, en especial la española, tuvo alguna brecha de entrada al espacio islámico, mediante la traducción?

CHRISTIAN TĂMAȘ. En primer lugar, quisiera aclarar que la lengua y la cultura árabe no son para nada marginalizadas. Diría todo lo contrario, aunque el interés en aumento del que goza actualmente, más que en otras épocas, se deba al pánico invocado. Es una lástima que una cultura tan valiosa se haya visto obligada a hacerse oír a través de semejantes manifestaciones de violencia.

En lo que concierne el espacio islámico, desde el punto de vista mental, está cerrado a la literatura religiosa cristiana. Es cierto que las obras completas de santa Teresa fueron traducidas al árabe por Antoine Khater y publicadas el año pasado gracias a los frailes carmelitas descalzos del Líbano y difundidas actualmente por Egipto, Irak y otros pocos países árabes. Pero esto no demuestra la actitud de los musulmanes hacia este tipo de escritos, sino únicamente los esfuerzos de los cristianos auténticos de dar a conocer sus valores y desmarcarse de aquellas acciones 
de los pueblos, estados y gobiernos que se tildan de cristianos, que el islam considera como una amenaza directa para su existencia.

AMELIA SANDU-ANDRIEȘ. Volvamos al espacio cultural rumano: tenemos aquí un público apresurado, a veces sujeto a prejuicios, algo desconfiado hacia los textos procedentes de otros horizontes de creencias religiosas. ¿Considera usted que la obra de santa Teresa ha encontrado su sitio en Rumanía, que es lo suficientemente bien conocida? ¿Se puede hacer algo para acercarla de modo más concreto al público rumano actual?

CHRISTIAN TĂMAȘ. Nunca un autor será suficientemente conocido en la Rumanía de nuestros días: a tenor de las últimas estadísticas, un 50\% de los rumanos no habrían abierto jamás un solo libro. Y si en la primera década después de la Revolución del 1989 se registró un aumento significativo de la lectura, parece que con el nuevo milenio las prioridades han cambiado de forma radical. Vivimos hoy en un mundo interconectado, marcado por desequilibrios económicos, ideológicos y políticos importantes, un mundo en el cual Dios o no significa nada, o significa demasiado. El mundo cristiano de la época de santa Teresa ya no existe. De hecho, ha dejado de existir del todo. La Iglesia se encuentra en la periferia de la sociedad humana, igual que la idea de Dios. Mammón reina a sus anchas por doquier, incluso entre nosotros, los rumanos, que nos jactamos de nuestras raíces cristianas bimilenarias.

Hoy por hoy (estamos en 2015) y en nuestra sociedad, no veo que se pueda hacer algo para acercar a santa Teresa, de modo concreto, como dice usted, al gran público. En nuestro país, santa Teresa ha encontrado un sitio suyo, según la disponibilidad del público pero, por desgracia, creo que deberá contentarse con esto. Entraron en un cono de sombra no sólo las obras de nuestra autora, sino muchas otras obras maestras universales. Los jóvenes apenas si saben algo de los grandes valores de la cultura rumana. En los años 90, sin embargo, santa Teresa significó bastante más. Recién salidos de la jaula del totalitarismo, los rumanos anhelaban recuperar el tiempo perdido, si se puede decir así, y obras como las de la escritora española, que traduje, gozaron de excelente acogida.

AMELIA SANDU-ANDRIEȘ. ¿Cualquier persona puede entender a Santa Teresa, en cualquier edad, en cualquier lugar, en cualquier circunstancia?

CHRISTIAN TĂMAȘ. El mensaje de santa Teresa no es fácil de entender y aceptar por cualquiera, a cualquier edad. Se necesita un cierto grado de madurez de pensamiento y, por encima de todo, la apropiación ontológica de una relación más o menos personal con Dios. Uno queda lejos de recibir el mensaje de la santa de Ávila si no está preparado a pronunciar, en lo más recóndito de su alma, «Domine, ut videam!» como el ciego de Jericó.

AMELIA SANDU-ANDRIEȘ. ¿Cree usted que la lectura de autores de la categoría de santa Teresa podría contribuir a paliar los efectos de la pobreza lingüística, la anemia semántica que observamos entre los adolescentes rumanos? 
CHRISTIAN TĂMAȘ. Sí, creo que sí, a condición de poder recibir con esta edad los escritos de santa Teresa. Pero resulta difícil que los adolescentes de hoy los lleguen a comprender, en Rumanía o en cualquier otra parte. Decíamos antes que para acercarse a santa Teresa sin intermediarios, hace falta un pensamiento maduro y unos conocimientos que, normalmente, se adquieren algo más tarde en la vida. Se necesita, además, un horizonte interior cuya formación y consolidación se construye con el paso de los años, mediante estudio y experiencias vitales.

AMELIA SANDU-ANDRIEȘ. ¿Leer a santa Teresa constituye una traición, en una sociedad ortodoxa, como lo es la sociedad rumana, en su mayoría?

CHRISTIAN TĂMAȘ. Sí, lo es, si uno es incapaz de ver más allá de sus narices y si, al ser ortodoxo, se considera nacido del muslo de Júpiter. Aún hay bastantes ejemplares de este tipo pero no se suelen contar entre los amantes de la lectura (los pocos que quedan), de forma que sus pareceres pesan mínimamente. En general, la cuestión relativa no sólo a la acogida de los escritos de santa Teresa, sino también de otros santos o teólogos no ortodoxos, se planteó poco en los términos restrictivos de una cultura marcadamente orientada a nivel de creencia religiosa y, mucho más, en los términos de la cultura en su sentido amplio. Desde este último punto de vista, buen número de obras de diversa índole religiosa fueron apreciadas en su justo valor, hace década y media.

AMELIA SANDU-ANDRIEȘ. Si tuviera que elegir un libro, ¿con cuál se quedaría?

CHRISTIAN TĂMAȘ. Difícil decirlo. Hay tantos libros que sustentaron la construcción del ser humano, a lo largo del tiempo... Si fuera a elegir, eligiría un libro que contuviera todos los demás. 